\title{
Prosthetic Treatment for Hemimaxillectomy Patient: (A Clinical Case)
}

Nashwah Subhi

BDS, MSc (Assist Lec)

Mohammed A Abdulla

$\mathrm{BDS}, \mathrm{MSc}$ (Lec)

Nadira A Hatim

BDS, MSc (Prof)
Department of Prosthetic Dentistry

College of Dentistry, University of Mosul

Department of Prosthetic Dentistry

College of Dentistry, University of Mosul

Department of Prosthetic Dentistry

College of Dentistry, University of Mosul

\footnotetext{
الخلاصة

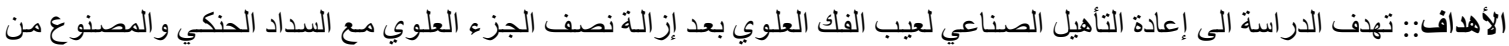

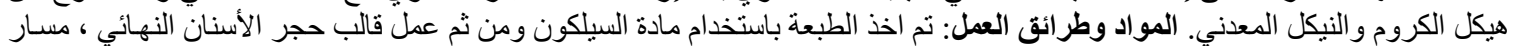

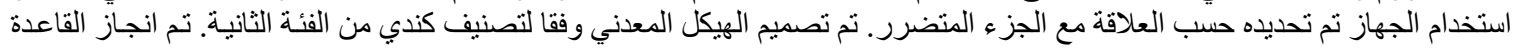

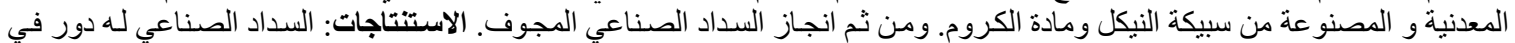

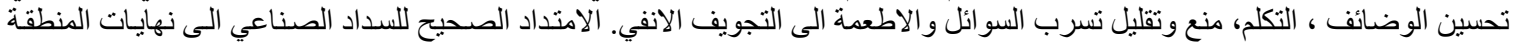
المتضررة ضروري لتحسين خاصية الثبات و الدعامى للسداد الصناعي.
}

\begin{abstract}
Aims: prosthetic rehabilitation of a maxillary defect after hemi-maxillectomy with a palatal obturator made from nickel chromium framework. Materials and methods: A silicon impression was made and poured with a dental stone to develop a definitive cast. The site, position and shape of maxillary defect determine the path of insertion. Design the metal framework of the obturator to Class II R.P.D according to Kennedy's classification. Casting the framework in base-metal alloy made from nickel chromium framework, centric jaw relation was recorded. A finished prosthesis (an obturator of closed hollow-bulb type) was inserted. Conclusions: Obturator prosthesis enhancing function and speech, reduce the rate of fluids and food passing to the nose. Extend the border of an acrylic of the prosthesis at defect site lead to enhance both the retention and stability of the obturator.
\end{abstract}

Key words: Obturator, Hemimaxillectomy

Subhi N, Abdulla MA, Hatim NA Prosthetic Treatment for Hemimaxillectomy Patient: (A Clinical Case). Al-Rafidain Dent J. 2018,18(1):67-72.

Received: 20/9/2018 Sent to Referees: 30/9/2018 Accepted for Publication: 7/4/2019

\section{INTRODUCTION}

Prosthodontists and maxillofacial surgeons used term maxillectomy to describe the total/partial resection of the maxillae in patients suffering from malignant or benign neoplasm. ${ }^{(1)}$ Part of the soft and hard palates often includes in the resultant surgical defect, that is results in an oro-antral communication. ${ }^{(2)}$ There are many organs that have an important roles in deglutition and speech, the hard and soft palate play the important role. When these structures partially or completely removed due to the surgery, a team work is critical. A dysfunction in swallowing and speech with clear reduction in quality of life, that caused by a surgical approach without obturation or reconstruction of the defect part in surgical 
field that will cause air, food particles, and fluid leakage into the nasal cavities and maxillary sinus. ${ }^{(3)}$ Defect size, position of remaining hard and soft tissues that have to be used in support, stabilize, and retain the prosthesis will determine success of the obturator. (4) Restoring of the lost stomatognathic apparatus and associated structures by a suitable artificial prosthesis are advocated, especially for large defects secondary to tumor resection. management of such patients need multidisciplinary medical team comprising the maxillofacial surgeon, prosthesis, oncologist/ radiotherapist, speech therapist ${ }^{(5)}$

Studies show that prosthodontic treatments was very successful for the rehabilitation of the speech in maxillary defect participants. ${ }^{(6)}$ Minimum parts loss in maxilla lead to clear raise in respiratory volume. Closing the defect efficiently an immediate respiratory effort record a normal level of respiratory volume and oral pressure is corrected with the normal limits for speech. ${ }^{(7)}$ An attempts to increase the retention of the obturator prosthesis is adding an attachment pieces will result huge benefits in speech and mastication function.

(8) More attempts to optimize retention and stability obtained by the design of the prosthesis that is to include the remaining natural dentition and tissue-bearing areas. An increasing height of the lateral wall obturator higher the scar band produce a longer lever arm from the rotation point and subsequently reduce the vertical slippage of the prosthesis, also engaging the anterior nasal aperture with the prosthesis will enhance this benefit. ${ }^{(9,10)}$ Conserve the remaining tooth structure and satisfied both functional and esthetic demands is clearly obtained by palatal obturator treatment for the patient with maxillary defect after hemimaxillectomy.

\section{MATERIALS AND METHODS}

\section{Case history}

A female 14- years old suffering from inverted papilloma stage $\mathrm{T} 2$ involving initial invasion of the floor of the left maxillary sinus, the left inferior nasal fossa, left hard palate, with the underwent inferior-anterior Maxillectomy (Figure 1), she was referred to Al-Jamhoury hospital, maxillofacial department (Mosul, Iraq).

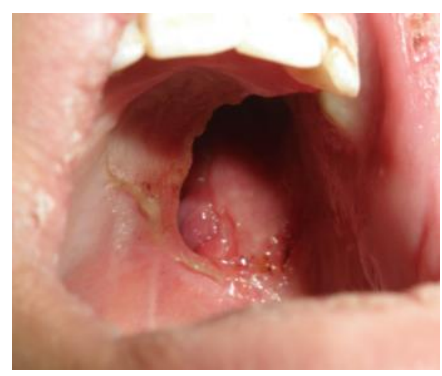

Figure (1): Intra-oral view following left maxillectomy 
Surgical resection was done followed with surgical obturator, follow up the case with healing process. Three months after surgical resection operations. An intraoral examination shows sound and healthy remaining teeth from the maxillary left lateral incisor to the right maxillary second molar for definitive obturator construction.

\section{Procedure}

1. A maxillary silicon impression (Badia,
Polesine/ Ravigo- 45021- Italy) was made (Figure 2), and poured with a dental stone (Elite model-Zhermack technical ISO 6873- Italy) to produce a definitive cast (Figure 3). The definitive casts with vertical and horizontal records were mounted and transfer the interarch relation to a semi-adjustable articulator (Hanau96 H2O; Water- Pik Technologies, Inc, FtCollins, Colo).

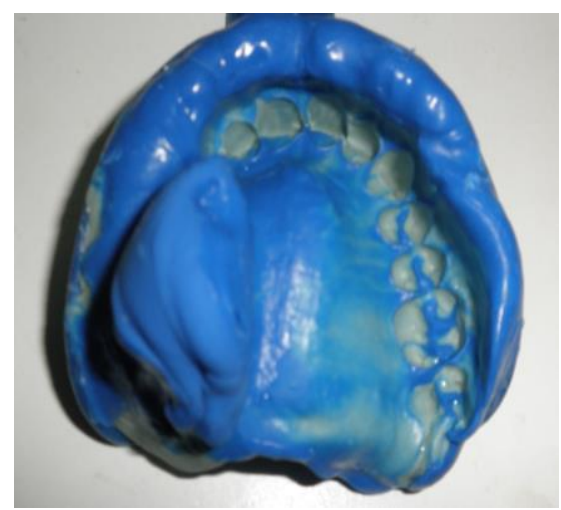

Figure (2): Asilicon impression

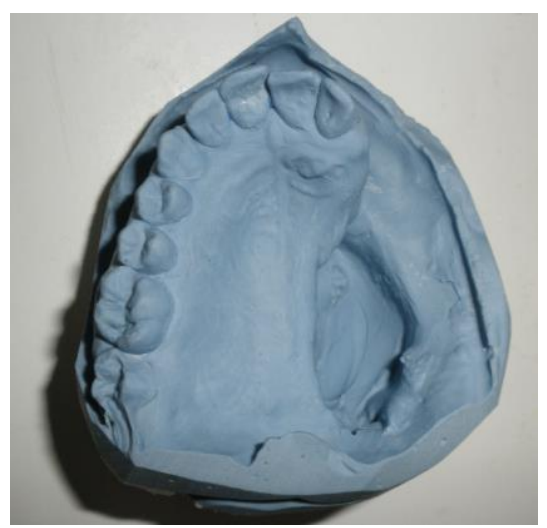

Figure (3): Definitive cast

The definitive casts with vertical and horizontal records were mounted and transfer the interarch relation to a semi-adjustable articulator (Hanau- 96 H2O; Water- Pik Technologies, Inc, Ft- Collins, Colo).

2. Surveying the master cast, and a direction of insertion and removal were designed in relation to the defect areas to gain a benefit from the tissue under cuts of the surgical site with optimal peripheral seal at the defect area.

3. The metal framework obturator was designed as Class II R.P.D according to Kennedy's classification. Tooth support, add the direct retainer near to the defect extension base, also 
add the indirect retention after abutment teeth preparations. The framework design then casted in alloy base-metal, this made from nickel chromium framework (Eisen bacher dental waren Ed GMBH, Gemany) (Figure. 4).

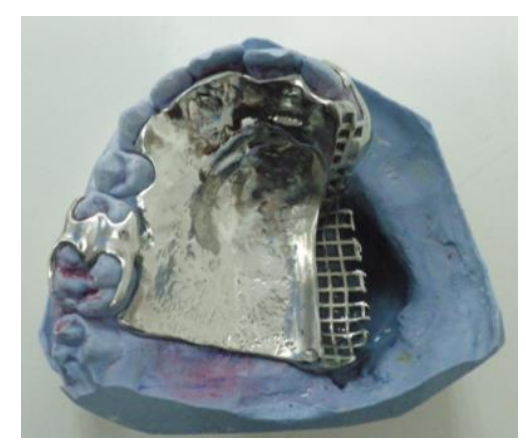

Figure (4): Obturator framework

4. Use a diamond type burs (Komet 6909; Gebr. and articulation paper, to djust the framework Brasseler GmbH and Co, Lemgo, Germany) to fabricate a suitable intraoral fit (Figure 5).

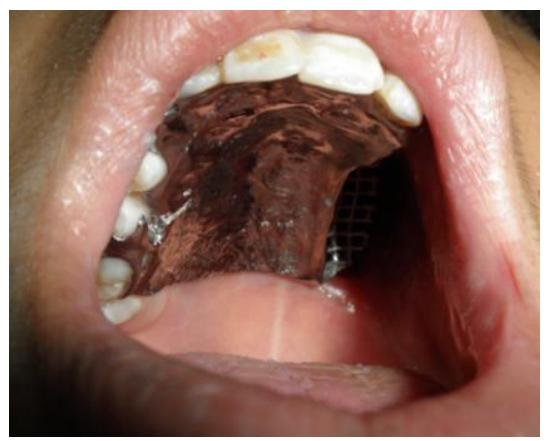

Figure (5): framework adjustment

5. After cast-framework adjustment, centric wax, Major Prodotti Dentari - S.P.A,/Italy) jaw relation was recorded using the then transfer to the articulator for mounting modeling wax (T.P.- Regular modeling procedure (Figure 6).

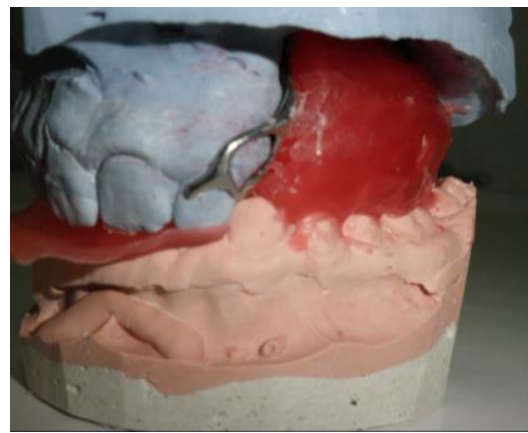

Figure (6): Mounting procedure 
6. Arrangement of an acrylic resin teeth (Anterior M, A2; Posterior M, A2, Seif, Syrian) and the occlusion against the lower natural dentition was done. A hollow-bulb obturator closed-type prosthesis was processed by an ordinary procedure using heat cured acrylic resin denture base material (Regular, Vertex dental,
Netherlands ISO 1567, Type 1, Class 1)

(Figure 7) with adequate thickness of acrylic to facilitate the reduction of an acrylic at the obturation site to compensate the shrinkage of the surrounding tissue during healing process after surgical operation and give support to the inner side of the cheek for profile improvement.

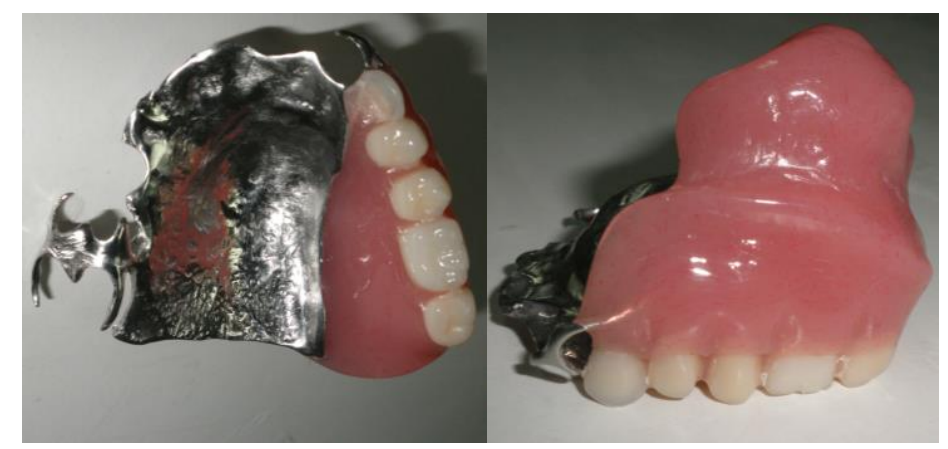

Figure (7): Obturator extra orally

7. Use pressure-indicating paste (Figure 8) to adjusttrbatment was pleased to the patient, and the patient obturator at the insertion appointment. Give an orabrded at adjustment appointment that the hygiene instructions . Final results of the whrtesthesis is comfortable and easily to be used.

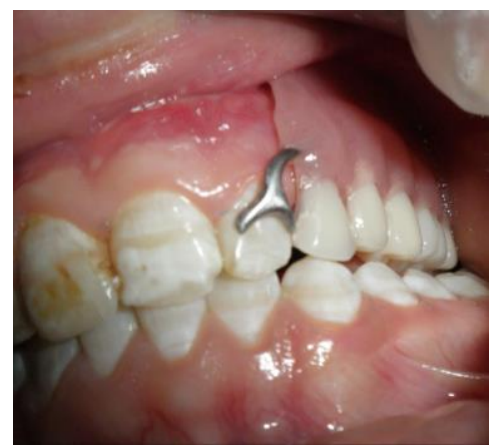

Figure (8): Obturator intra orally 


\section{DISCUSSION}

A multidisciplinary expertise is required to achieve a suitable speech, swallowing and functional outcomes of the construction successful prosthesis of a partial unilateral maxillectomy destruction that considered as a challenging treatment procedure . In partially edentulous patients, it may be preferred to complete resection of soft palate over partial resection to gain a clear access to posterior and lateral wall of pharynx. Complete all the construction steps of the obturator from the wax try-in step, provide a good control of the obturator thickness, then reducing the overall weight produce a virtually water- tight seal of the prosthesis. ${ }^{(11)}$

\section{CONCLUSIONS}

Obturator prosthesis enhancing function and speech, prevent liquid and food to leak to the nasal cavity. Acrylic resin extension at the defect site lead to enhance both of retention and stability of the obturator.

\section{REFERENCES}

1. Spiro RH, Strong EW, Shah JP. Maxillectomy and its classification. Head Neck 1997:309314.

2. Cummings CW. Cummings otolaryngology: head \& neck surgery. 4th ed. St. Louis: Elsevier; 2004. p. 1604-1608.

3. Jacob FJ. Clinical management of the edentulous maxillectomy patient. In: Taylor
TD (editor). Clinical maxillofacial prosthetics. Chicago: Quintessence. 2000. p. 85-87.

4. Watson RM, Gray BJ. Assessing effective obturation. J Prosthet Dent. 1985; 54(1):88-93.

5. Cheng AC, Somerville DA, Wee AG. Altered prosthodontic treatment approach for bilateral complete maxillectomy: A clinical report. $J$ Prosthet Dent. 2004; 92(2):120-124.

6. Chen C, Ren W, Gao L, Cheng Z, Zhang L, Li S, Zhi P. Function of obturator prosthesis after maxillectomy and prosthetic obturator rehabilitation. Braz J Otorhinolaryngol. 2016; 82(2): 177-183.

7. Rieger J, Wolfaardt J, Selkay H, Jha N. Speech outcomes in patients rehabilitated with maxillary Obturator prosthesis after Maxillectomy: A prospective study. Int $J$ Prosthodont. 2002; 15: 139- 144.

8. Dalkiz M,D and Dalkiz A. The Effect of Immediate Obturator Reconstruction after Radical Maxillary Resections on Speech and other Functions. Dent. J. 2018; 6(3): 22.

9. Minsley GF, Warren MN, Hinton V. Physiologic responses to maxillary resection and subsequent obturation. J Prosthet Dent. 1987;57(3):388-444.

10. Barry H, and Carl F. Driscoll. Fabrication of a closed hollow obturator J Prosthet Dent. 2004; 91(4): 383-385.

Shinde B, Jadhav G, and Mittal P. Hollow Bulb Obturator Prosthesis Following Palatal Resection: A Case Report. Glob J Oral Sci. 2016; 2:6-9. 